\title{
Bilangan Kromatik Pewarnaan Titik pada Graf Dual dari Graf Roda
}

\author{
Muhammad Abdy ${ }^{1, \text { a) }}$, Rahmat Syam ${ }^{1, b)}$, dan Tina ${ }^{1, c)}$ \\ ${ }^{1}$ Jurusan Matematika, Fakultas Matematika dan Ilmu Pengetahuan Alam \\ ${ }^{2}$ Universitas Negeri Makassar \\ a) muh.abdy@unm.ac.id \\ b) rahmat.syam@unm.ac.id \\ c)tina10787@gmail.com
}

\begin{abstract}
Abstrak. Penelitian ini bertujuan mengkonstruksi graf dual dari graf roda $\left(W_{n}{ }^{*}\right)$ dan menentukan bilangan kromatik graf dual dari graf roda $\left(W_{n}{ }^{*}\right)$. Penelitian ini dimulai dari menggambarkan beberapa graf roda $W_{n}$ dari $W_{3}$ ke $W_{8}$, kemudian membangun graf dual dari graf roda $W_{n}$ dengan memanfaatkan graf-graf dari $W_{3}$ ke $W_{8}$, kemudian memberikan warna pada titik-titik dari graf dualnya dengan menentukan bilangan kromatiknya. Diperoleh hasil bahwa Graf roda $W_{n}$ merupakan graf self-dual karena isomorfik dengan graf dualnya yaitu $W_{n}^{*}$. Pewarnaan titik diperoleh dengan menentukan bilangan kromatik graf dual dari graf roda, menentukan pola dari bilangan kromatik, dan memberikan warna. Berdasarkan hasil penelitian, diperoleh bilangan kromatik pewarnaan titik pada graf dual dari graf roda yakni

$$
X\left(W_{8}^{*}\right)= \begin{cases}4 & n \text { bilangan ganjil, } n \geq 3 \\ 3 & n \text { bilangan genap, } n \geq 3\end{cases}
$$
\end{abstract}

Kata Kunci: Pewarnaan Titik, Bilangan Kromatik, Graf Dual dan Graf Roda.

\begin{abstract}
This research aims to construct a dual graph from a wheel graph $\left(W_{n}{ }^{*}\right)$ and determine the dual graph chromatic number of the wheel graph $\left(W_{n}{ }^{*}\right)$. This research starts from describing some wheel graph $W_{n}$ from $W_{3}$ to $W_{8}$, then construct a dual graph from a wheel graph $W_{n}$ from $W_{3}$ to $W_{8}$, then gives color to the vertices of the dual graph by determining the chromatic number. The result showed that the wheel graph $W_{n}$ is a self-dual graph because it is isomorphic with its dual graph, namely $W_{n}$. The vertex coloring is obtained by determining the chromatic number of the dual graph of the wheel graph, determining the pattern of the chromatic number and giving the color. Based on the research results, the chromatic number of vertex coloring on dual graph of a wheel graph is:
\end{abstract}

$$
X\left(W_{8}^{*}\right)=\left\{\begin{array}{cc}
4 & n \text { is odd number, } n \geq 3 \\
3 & n \text { is even number }, n \geq 3
\end{array}\right.
$$

Keywords: Vertex Coloring, Chromatic Number, Dual Graph and Wheel Graph.

\section{LATAR BELAKANG}

Salah satu pokok bahasan dalam teori graf adalah graf roda. Graf roda merupakan graf yang dibentuk dari operasi joint graph antara graf sikel dan graf komplit (Assadillah, 2009). Salah satu macam bentuk graf adalah graf planar. Graf planar adalah graf yang dapat digambarkan pada bidang datar dengan sisi-sisi yang tidak saling memotong (Muhib, 2013). Adapun konsep yang berkaitan dengan graf yaitu pewarnaan graf. Pewarnaan graf adalah suatu bentuk pelabelan graf dengan cara memberikan warna pada elemen graf yang dapat dijadikan subjek dalam memahami constraint permasalahan. Ada tiga macam persoalan pewarnaan graf (graph colouring) yaitu 
pewarnaan titik, pewarnaan sisi, dan pewarnaan wilayah atau region graf roda, planar, pewarnaan graf (Mahardika \& Marcos, 2017). Karena ketiga hal ini berkaitan dengan bilangan kromatik maka perlu diketahui pengertian dari bilangan kormatik itu sendiri. Bilangan kromatik merupakan sasaran utama dari pewarnaan titik pada suatu graf, dimana bilangan kromatik menunjukkan minimum banyaknya warna yang diperlukan untuk mewarnai semua titik pada graf, sedemikian sehingga setiap dua titik yang berhubungan langsung mendapatkan warna yang berbeda (Setiawan, 2012). Dengan demikian pewarnaan graf merupakan aplikasi yang erat kaitannya dengan penentuan bilangan kromatik. Pada penelitian ini akan dibahas mengenai bilangan kromatik pewarnaan titik pada graf dual dari graf roda $\left(\mathrm{W}_{\mathrm{n}} *\right)$. Untuk menentukan graf dual, mulamula dibuat percobaan untuk menentukan bilangan kromatik menggunakan algoritma welchpowell. Setelah bilangan kromatik diketahui tinggal menentukan banyaknya titik graf dual dari graf roda, sehingga titik yang terhubung langsung mempunyai warna yang berbeda (Supriyandi \& Eka, 2018). Penelitian terkait pewarnaan graf telah dilakukan beberapa peniliti, diantaranya Mahardika dan Marcos (2017) meneliti tentang penerapan algoritma graf Welch Powel pada penjadwalan mata kuliah dan jadwal asisten study kasus forum asisten STMIK AMIKOM Purwokerto, pada penelitian tersebut menghasilkan graf berdasarkan data jadwal asistensi dan perkuliahan masing-masing anggota, kemudian diterapkan algoritma welch-powell dalam melakukan pewarnaan titik untuk memperoleh jadwal yang sesuai. Sejalan dengan penelitian Muhib (2013) tentang Bilangan Kromatik Pewarnaan Titik pada Graf Dual dari Graf Piramida $\left(\operatorname{Pr}_{\mathrm{n}}{ }^{*}\right)$ yang merupakan penelitian pengembangan yang telah dilakukan sebelumnya, dimana dikontruksi graf dual dari graf roda dan menentukan bilangan kromatik graf dual dari graf roda dengan menggunakan penerapan algoritma pada penelitian yang dilakukan oleh Mahardika dan Marcos (2017).

Langkah-langkah yang ditempuh adalah sebagai berikut; 1) Menggambarkan graf roda $\left(W_{n}\right)$ dari $W_{3}$ sampai $\left.W_{8} ; 2\right)$ Mengkontruksi graf dual dari graf roda $\left(W_{n}\right) W_{3}$ sampai $W_{8} ; 3$ ) Menentukan bilangan kromatik pewarnaan titik graf dual dari graf roda $\left(W_{n}\right) W_{3}$ sampai $\left.W_{8} ; 4\right)$ Melabel titik dengan derajatnya, label titik $\left.v_{1}, v_{2}, \ldots v_{n} ; 5\right)$ Memberikan warna pada titik $W_{3}$ sampai $W_{8} ; 6$ ) Menentukan Bilangan Kromatik pewarnaan graf dual.

\section{HASIL PENELITIAN DAN PEMBAHASAN}

\section{Graf dual}

Graf bidang $G$ akan mempartisi bidang ke dalam sejumlah wilayah (region) yang saling terhubung. Batas dari suatu region adalah titik-titik dan sisi-sisi yang membatasi wilayah tersebut. Setiap graf bidang mempunyai satu region yang tidak terbatas yang disebut region luar, region selain region luar disebut dengan region dalam Muhib (2013).

Misalkan $G$ adalah suatu graf bidang. Didefinisikan graf baru $\mathrm{G}^{*}$ sebagai berikut. Masing-masing region pada $G$ diwakili oleh titik pada $G^{*}$. Dua titik a dan b pada $G^{*}$ akan saling terhubung langsung jika dan hanya jika region yang diwakili oleh dua titik itu saling berbatasan langsung di G. Graf $\mathrm{G}^{*}$ ini kemudian disebut graf dual (dual graph) dari G Muhib (2013). Suatu Graf dikatakan self-dual jika graf tersebut isomorfik dengan graf dualnya, dimana dua buah graf $\mathrm{G}$ dan $\mathrm{H}$ dikatakan isomorfik, bisa ditulis $G \cong H$ jika terdapat fungsi bijektif $f: V(G) \rightarrow V(H)$ sedemikian hingga $u, v \in V(G)$ jika dan hanya jika $f(u), f(v) \in V(H)$ terhubung langsung.

\section{Algoritma Welch-Powell}

Algoritma Welch-Powell merupakan salah satu algoritma pewarnaan graf untuk pewarnaan berdasarkan derajat tertinggi dari titik-titiknya atau disebut Largest Degree Ordering /LDO. Algoritma Welch-Powell merupakan cara yang efisien dalam pewarnaan graf (Hasanah, 2012). 


\section{Pewarnaan Graf}

Pewarnaan graf (graph coloring) adalah pemberian warna pada vertex sedemikian rupa sehingga tidak ada dua buah vertex yang adjacent (terhubung langsung) memiliki warna yang sama dan penggunaan warna diusahakan sesedikit mungkin (Dewi, 2010).

\section{Pewarnaan Titik}

Pewarnaan titik adalah memberi warna berbeda pada titik yang terhubung langsung sehingga tidak ada dua titik yang terhubung langsung mempunyai warna yang sama. Dalam pewarnaan graf, tidak hanya sekedar mewarnai titik-titik dengan warna yang berbeda dari warna titik yang terhubung langsung saja, tetapi juga menginginkan jenis warna yang digunakan seminimum mungkin.

\section{Bilangan Kromatik}

Bilangan kromatik dinotasikan $\chi(G)$, adalah bilangan bulat terkecil $k$ sehingga graf $G$ mempunyai pewarnaan titik sejati dengan $k$ warna (Puspasari \& Dafik, 2014).

Teorema 1 (Welyyanti, 2008)

Jika ada sebuah pewarnaan - $k$ pada graf $G$, maka $\chi(G) \leq k$

Teorema 2 (Welyyanti, 2008)

Misalkan $G$ graf tak kosong, graf $G$ bipartisi jika dan hanya jika $\chi(G)=2$.

Dimana graf bipartisi merupakan graf yang himpunan titiknya dapat dipisahkan menjadi dua himpunan tak kosong $X$ dan $Y$ sehingga masing- masing sisi di graf tersebut menghubungkan satu titik di $X$ dan satu titik di $Y$ (Welyyanti, 2008).

Pembahasan bilangan kromatik pada pewarnaan titik graf dual dari graf roda $W_{n}^{*}$ dibatasi untuk $n$ $\geq 3$ dan $n$ bilangan asli.

\section{Mengkonstruksi Graf Dual dari Graf Roda}

\section{Graf Dual dari Graf Roda $W_{3}$}

Dalam menentukan graf dual dari graf roda, mula-mula diperhatikan adalah cara membangun graf roda. Graf roda $\left(W_{n}\right)$ adalah graf yang memuat satu sikel yang setiap titik pada sikel terhubung langsung dengan titik pusat. Graf roda $\left(W_{n}\right)$ diperoleh dengan operasi penjumlahan graf sikel $C_{n}$ dengan graf komplit $K_{1}$. Penjumlahan dari $G 1$ dan $G 2$ ditulis $G=G 1+G 2$ adalah graf dengan $V(G)=V(G 1) \cup V(G 2)$ dan $E(G)=E(G 1) \cup E(G 2) \cup\{u v \mid u \in V(G 1)$ dan $v \in V(G 2)\}$ (Abdussakir, 2009). Sehingga cara membangun graf roda $\left(W_{n}\right)$ adalah menambahkan $K_{1}$ pada graf sikel $C_{n}$, kemudian setiap titik pada $C_{n}$ dihubungkan langsung dengan $K_{1}$. Graf Roda $W_{3}$ disajikan pada Gambar 1 dan untuk menentukan graf dual dari graf roda $W_{3}$ perhatikan Gambar 2. 


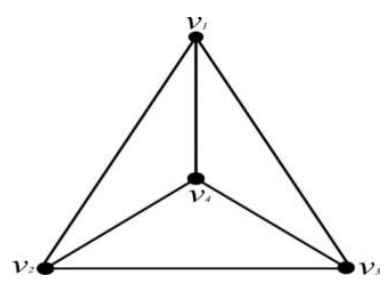

(a) GAMBAR 1. Graf Roda $W_{3}$

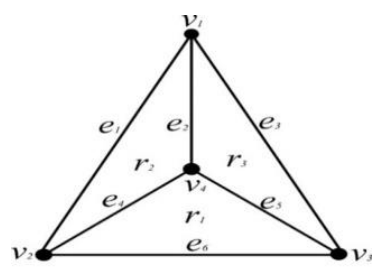

$r$

(b) GAMBAR 2. Graf Roda $W_{3}$

Gambar 2 adalah graf roda dengan 4 titik, yang diberi nama dengan titik $v_{1}, v_{2}, v_{3}, v_{4}$, mempunyai 6 sisi $e_{1}, e_{2}, e_{3}, e_{4}, e_{5}, e_{6}$ dan mempunyai 4 region $r_{1}, r_{2}, r_{3}, r_{4}$.

$$
\begin{array}{ll}
V\left(W_{3}\right)=\left(v_{1}, v_{2}, v_{3}, v_{4}\right) & \left|V\left(W_{3}\right)\right|=4 \\
E\left(W_{3}\right)=\left(e_{1}, e_{2}, e_{3}, e_{4}, e_{5}, e_{6}\right) & \left|E\left(W_{3}\right)\right|=6 \\
R\left(W_{3}\right)=\left(r_{1}, r_{2}, r_{3}, r_{4}\right) & \left|R\left(W_{3}\right)\right|=4
\end{array}
$$

Didefinsikan graf $W_{n}^{*}$ adalah graf dual dari $W_{n}$, maka graf dual dari Gambar 2 dapat digambarkan seperti berikut.

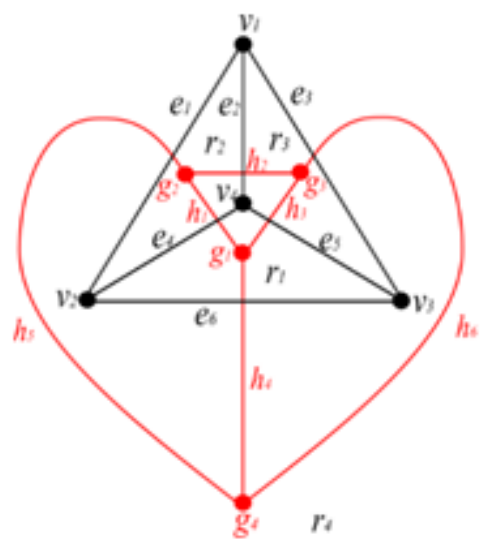

(a) GAMBAR 3. $W_{3}$ dan $W_{3}^{*}$

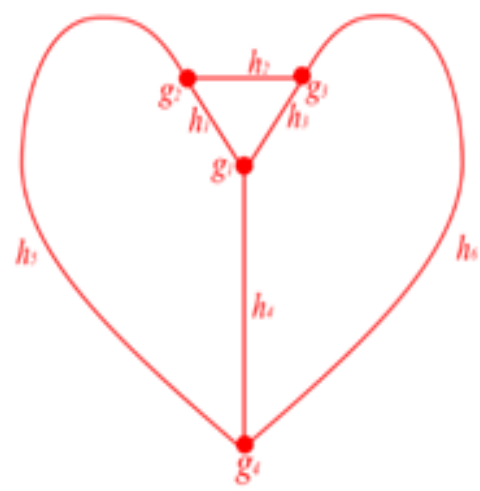

(b) GAMBAR 4. $W_{3}^{*}$

Gambar 3 menunjukkan graf roda $W_{3}$ dan $W_{3}^{*}$, serta Gambar 4 adalah graf dual yang dihasilkan pada Gambar 3 yang dinotasikan $W_{3}^{*}$. Perhatikan Gambar 3 yang warna hitam, mula-mula sebuah graf roda mempunyai 4 titik yang disebut graf roda $W_{3}$. Kemudian jika graf roda $W_{3}$ tersebut di dualkan, maka setiap region diwakili dengan sebuah titik, dimana titik-titik tersebut akan saling terhubung langsung jika dan hanya jika region yang diwakili oleh titik tersebut saling berbatasan langsung yang ditunjukkan pada Gambar 4. Kemudian jika Gambar 3 yang berwarna merah digambar ulang, yaitu titik yang mewakili region luar dari graf roda $W_{3}$ dalam hal ini titik $g_{4}$ dipindahkan kedalam maka akan terbentuk graf baru yang mempunyai bentuk yang sama dengan graf asalnya yaitu graf roda $W_{3}$, karena graf $W_{3}$ memiliki bentuk yang sama dengan dualnya sehingga graf $W_{3}$ isomorfik dengan $W_{3}^{*}$, akibatnya graf $W_{3}$ disebut graf self-dual. Graf dual $W_{3}^{*}$ merupakan graf terhubung karena setiap dua titik di graf dual $W_{3}^{*}$ terdapat lintasan yang menghubungkan kedua titik tersebut. Setiap titik di graf dual $W_{3}^{*}$ yang mewakili region dalam berderajat 3 dan titik di graf dual $W_{3}^{*}$ yang mewakili region luar berderajat 3. Graf dual $W_{3}^{*}$ memiliki 4 titik dan 6 sisi. Kemudian dengan langkah-langkah yang sama akan diperoleh graf dual dari graf roda $W_{4}^{*}, W_{5}^{*}, W_{6}^{*}, W_{7}^{*}, W_{8}^{*}$. 
Berdasarkan pembahasan graf dual dari graf roda $W_{3}^{*}, W_{4}^{*}, W_{5}^{*}, W_{6}^{*}, W_{7}^{*}, W_{8}^{*}$ dihasilkan tabel 1.

TABEL 1. Tabel Graf Dual

\begin{tabular}{ccc}
\hline No & Graf & $\begin{array}{c}\text { Bentuk Graf } \\
\text { Dualnya }\end{array}$ \\
\hline 1 & $W_{3}$ & $W_{3}$ \\
2 & $W_{4}$ & $W_{4}$ \\
3 & $W_{5}$ & $W_{5}$ \\
4 & $W_{6}$ & $W_{6}$ \\
5 & $W_{7}$ & $W_{7}$ \\
6 & $W_{8}$ & $W_{8}$ \\
\hline
\end{tabular}

\section{Pewarnaan Titik Graf Dual dari Graf Roda}

Pewarnaan titik adalah memberi warna berbeda pada titik yang terhubung langsung sehingga tidak ada dua titik yang terhubung langsung mempunyai warna yang sama.

\section{Pewarnaan Graf Dual $W_{3}^{*}$}

Langkah-langkah pewarnaan titik pada graf dual $W_{3}^{*}$ menggunakan algoritma Welch-Powell adalah sebagai berikut:

1) Karena semua titik pada graf dual $W_{3}^{*}$ memiliki derajat yang sama yaitu 3, maka dapat dipilih sebarang titik, kita pilih titik $g_{4}$ kemudian diberi warna-1, karena titik $g_{4}$ terhubung langsung dengan semua titik maka titik lain memiliki warna yang berbeda dengan titik $g_{4}$.

2) Pilih titik $g_{1}$ kemudian diberi warna-2, karena tidak ada titik yang belum di warnai dan tidak terhubung langsung dengan titik $g_{1}$ maka titik lain memiliki warna yang berbeda dengan titik $g_{1}$.

3) Pilih titik $g_{2}$ kemudian diberi warna-3, karena tidak ada titik yang belum di warnai dan tidak terhubung langsung dengan titik $g_{2}$ maka titik lain memiliki warna yang berbeda dengan titik $g_{2}$.

4) Pilih titik $g_{3}$ kemudian diberi warna-4.

5) Semua titik telah diwarnai.

Dengan langkah-langkah yang sama maka pewarnaan titik pada graf dual $W_{4}^{*}, W_{5}^{*}, W_{6}^{*}, W_{7}^{*}, W_{8}^{*}$ menggunakan algoritma Welch-Powell diperoleh pola bilangan kromatik pada pewarnaan titik graf dual $W_{n}^{*}$ sebagai berikut :

$$
\begin{aligned}
& X\left(W_{3}^{*}\right)=4 \\
& X\left(W_{4}^{*}\right)=3 \\
& X\left(W_{5}^{*}\right)=4 \\
& X\left(W_{6}^{*}\right)=3 \\
& X\left(W_{7}^{*}\right)=4 \\
& X\left(W_{8}^{*}\right)=3
\end{aligned}
$$

diperoleh pola graf dual dari graf roda

$$
X\left(W_{n}^{*}\right)= \begin{cases}4 & n \text { bilangan ganjil, } n \geq 3 \\ 3 & n \text { bilangan genap, } n \geq 3\end{cases}
$$




\section{Bukti}

Perhatikan bahwa karena graf yang mewakili region dalam pada graf $W_{n}$ selalu membentuk graf sikel $C_{n}$ dan titik yang mewakili region luar pada graf $W_{n}$ terhubung langsung dengan semua titik yang mewakili region dalam sehingga warna titik yang mewakili region luar harus berbeda dengan warna titik yang mewakili region dalam. Sehingga cukup dibuktikan

Perhatikan :

$$
X\left(C_{n}\right)=\left\{\begin{array}{l}
3, \quad \text { jika } n \text { bilangan ganjil }, n \geq 3 \\
2, \quad \text { jikan bilangan genap, } n \geq 3
\end{array}\right.
$$

Diketahui bahwa $C_{n}$ adalah graf sikel sehingga $C_{n}$ adalah graf tak kosong. Misalkan $C_{n}$ adalah sikel dengan $n$ titik, maka panjang sikel $C_{n}$ adalah $n$.

1) Jika $n$ genap maka $C_{n}$ adalah graf bipartisi sehingga berdasarkan Teorema 2 bilangan kromatik $C_{n}$ adalah 2.

2) Jika n ganjil maka $C_{n}$ bukan graf bipartisi, maka Berdasarkan Teorema $2 \chi\left(C_{n}\right) \neq 2$, dan karena $C_{n}$ bukan graf kosong, maka $\chi\left(C_{n}\right) \neq 1$ Sehingga $\chi\left(C_{n}\right) \geq 3$. Selanjutnya misalkan $V\left(C_{n}\right)=\left(V_{1}, V_{2}, V_{3}, \ldots, V_{n}\right)$. Untuk n ganjil dan $1 \leq \mathrm{i} \leq n-2$, warnai titik $V_{i}$ dengan warna 1 . Untuk $n$ genap dan $1 \leq \mathrm{i} \leq n-1$, warnai titik $V_{i}$ dengan warna 2 . Akhirnya warnai titik $V_{n}$ harus dengan warna 3. Maka diperoleh sebuah pewarnaan-3 pada $C_{n}$. Berdasarkan Teorema 1 , maka $\chi\left(C_{n}\right) \leq 3$. Karena $\chi\left(C_{n}\right) \geq 3$ dan $\chi\left(C_{n}\right) \leq 3$, maka $\chi\left(C_{n}\right)=3$.

Jadi untuk $C_{n}$ dengan $n$ titik maka untuk $n$ genap maka $\chi\left(C_{n}\right)=2$ dan untuk $n$ ganjil maka $\chi\left(C_{n}\right)=3$.

Dengan terbuktinya

$$
X\left(C_{n}\right)=\left\{\begin{array}{l}
3, \quad \text { jika } n \text { bilangan ganjil, } n \geq 3 \\
2, \quad \text { jika } n \text { bilangan genap, } n \geq 3
\end{array}\right.
$$

sehingga terbuktilah

$$
X\left(W_{n}^{*}\right)= \begin{cases}4, & n \text { bilangan ganjil }, n \geq 3 \\ 3, & n \text { bilangan genap, } n \geq 3\end{cases}
$$

\section{KESIMPULAN}

Berdasarkan hasil penelitian yang telah diuraikan, diperoleh kesimpulan sebagai berikut:

1. Graf dual $W_{n}^{*}$ berbentuk sama dengan asalnya yaitu graf roda $W_{n}$, dengan kata lain graf roda $W_{n}$ adalah graf self-dual karena isomorfik dengan graf dualnya. Graf dual $W_{n}^{*}$ memiliki karakteristik merupakan graf terhubung, Setiap titik di graf dual $W_{n}^{*}$ yang mewakili region dalam berderajat 3 dan titik di graf dual $W_{n}^{*}$ yang mewakili region luar berderajat $n$, dan graf dual $W_{n}^{*}$ memiliki sebanyak $n+1$ titik dan $2 n$ sisi. Karena graf $W_{n}$ merupakan graf self-dual, sehingga karakteristik yang dimiliki oleh graf dual $W_{n}^{*}$ juga dimiliki oleh graf $W_{n}$.

2. Pola bilangan kromatik pada pewarnaan titik graf dual $W_{n}^{*}$ sebagai berikut

$$
X\left(W_{n}^{*}\right)=\left\{\begin{array}{l}
4, \quad n \text { bilangan ganjil, } n \geq 3 \\
3, \quad n \text { bilangan genap, } n \geq 3
\end{array}\right.
$$




\section{SARAN}

Penelitian ini hanya memfokuskan cara mengkonstruksi graf dual dan menentukan bilangan kromatik graf dual dari suatu graf yakni graf roda. Sehingga untuk penelitian selanjutnya disarankan menggunakan suatu graf lainnya yang belum dikaji, dan bagaimana jika mencari indeks kromatik graf dual dari graf roda.

\section{DAFTAR PUSTAKA}

Abdussakir. (2009). Teori Graf. Malang: UIN Malang Press.

Assadillah, M. H. (2009). Dari Graf Roda $\left(W_{n}\right)$ dan Graf Gear $\left(G_{n}\right)$ (Skripsi). Universitas Islam Negeri, Malang.

Dewi, F. K. S. (2010). Pembangun Perangkat Lunak Pembangkit Jadwal Kuliah dan Ujian dengan Metode Pewarnaan Graf. Jurnal Buana Informatika, 1(1), 57-68.

Hasanah, U. (2012). Modifikasi Algoritma Welch-Powell untuk Pewarnaan Graf (Vertex Colouring) pada Penjadwalan Kuliah Jurusan Matematika Fakultas Sains Dan Teknologi UIN Suska Riau (Skripsi). Universitas Islam Negeri Sultan Syarif Kasim Riau, Pekan Baru.

Mahardika, F., \& Marcos, H. (2017). Penerapan Algoritma Graf Welch Powel pada Penjadwalan Mata Kuliah dan Jadwal Asisten Study Kasus Forum Asisten Stmik Amikom Purwokerto. Jurnal Simetris, 8 (2). 825-832.

Muhib. (2013). Bilangan Kromatik Pewarnaan Titik pada Graf Dual dari Graf Piramida (Pr $\left.{ }_{n}{ }^{*}\right)$ (Skripsi). Universitas Islma Negeri Maulana Malik Ibrahim, Malang.

Puspasari, D. S., \& Dafik. (2014). Pewarnaan Titik pada Graf Khusus: Operasi dan Aplikasinya. Prosiding Seminar Nasional Matematika, 1(1), 50-58.

Setiawan, I. 2012. Pewarnaan Graf dan Aplikasinya (Skripsi). Universitas Negeri Makassar, Makassar.

Supriyandi \& Eka, M. (2018). Penerapan Teknik Pewarnaan Graph pada Penjadwalan Ujian dengan Algoritma Welch-Powell. Jurnal Ilmu Komputer dan Informatika, 3(1), 58-63.

Welyyanti, D. (2018). Beberapa Syarat Cukup untuk Bilangan Kromatik Lokasi Hingga pada Graf Tak Terhubung. Jurnal Eksakta, 19(1), 76-82. 